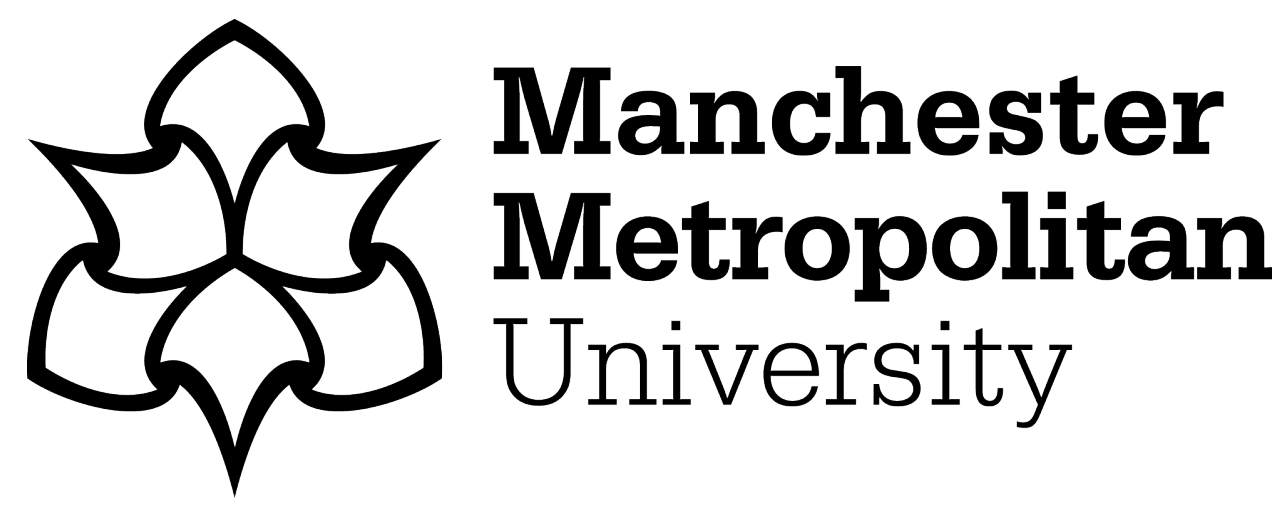

Croston, Michelle, Petrak, Jenny and Ustianowski, Andrew (2017) Use of the wellness thermometer to improve consultations for patients with human immunodeficiency virus. Nursing Standard, 31 (41). pp. 46-53. ISSN 00296570

Downloaded from: https://e-space.mmu.ac.uk/627711/

Version: Accepted Version

Publisher: RCN Publishing Ltd.

DOI: https://doi.org/10.7748/ns.2017.e10411

Please cite the published version 


\title{
Use of the wellness thermometer to improve consultations for patients with human immunodeficiency virus
}

\author{
Croston M, Petrak J, Ustianowski A (2017) Use of the wellness thermometer to improve consultations for patients with \\ human immunodeficiency virus. Nursing Standard. 31, 41, 46-53. \\ Date of submission: I2 January 2016; date of acceptance: 7 April 2017. doi: 10.7748/ns.2017.el04II
}

\author{
Michelle Croston \\ Specialist nurse, \\ infectious diseases, \\ North Manchester General \\ Hospital, Manchester, \\ England

\section{Jenny Petrak} \\ Consultant clinical \\ psychologist, Homerton \\ University Hospital, \\ London, England

\section{Andrew Ustianowski Consultant, infectious diseases, North Manchester General Hospital, Manchester, England}

\section{Correspondence michelle.croston@yahoo. com}

\section{Conflict of interest} None declared

\section{Peer review}

This article has been subject to external double-blind peer review and checked for plagiarism using automated software

\begin{abstract}
The care paradigm for patients with human immunodeficiency virus (HIV) has changed from managing an infectious condition with a suboptimal prognosis, to managing a long-term chronic disease. The wellness thermometer is a tool that was developed to assist with monitoring the biological, psychological, social and spiritual well-being of patients with HIV.

Aim To evaluate the effectiveness of using the wellness thermometer in healthcare consultations with patients with HIV.

Method This was a service evaluation that was undertaken in three UK HIV clinics in 2014. After using the wellness thermometer, patients and healthcare professionals completed a survey to indicate whether they felt the tool improved their consultations.

Results A total of 231 patients completed the survey. It was found that $80 \%(n=\mid 85)$ of patients felt the wellness thermometer helped to identify their concerns, while $79 \%$ ( $n=182$ ) of patients felt the wellness thermometer improved their conversation with the healthcare professional. Of the 12 healthcare professionals who completed the survey, most felt that the tool helped patients to identify their concerns $(n=10)$ and that it was easy to use ( $n=11)$.

Conclusion There are several benefits associated with using the wellness thermometer in healthcare consultations, and it may support patients with HIV to report any concerns they have in relation to their treatment and quality of life. The authors envisage that the tool will become a routine part of the care of these patients.
\end{abstract}

\section{Keywords}

communicable diseases, communication, HIV, human immunodeficiency virus, long-term conditions, quality of life, quantitative research, well-being, wellness thermometer

THE TREATMENT OF human immunodeficiency virus (HIV) has changed significantly since the introduction of the first antiretroviral therapies and subsequent combination therapies (Antiretroviral Therapy Cohort Collaboration 2008, Thompson et al 2012). Mortality rates have declined, with an increase in life expectancy for patients with HIV of around 13 years between 1996-1999 and 2003-2005 (Antiretroviral Therapy Cohort Collaboration 2008).

Life expectancy for a 20-year-old individual with HIV who is receiving antiretroviral therapies in the US, Canada or UK is comparable to the life expectancy of a 20-year-old person in the general population, often living into their early 70s (Samji et al 2013). This is, in part, a result of antiretroviral therapy becoming increasingly tolerable, advances in HIV treatment meaning that patients are required to take fewer medicines as well as the reduced side effects of these medicines, alongside an increase in the timely diagnosis of HIV (Antiretroviral Therapy Cohort Collaboration 2008, Thompson et al 2012). 
While the care paradigm for HIV has changed from caring for patients with an infectious disease and suboptimal prognosis, to long-term chronic infection treatment (Degroote et al 2013), new challenges have emerged from this change that affect the quality of life of patients with the condition, such as the burden of lifelong adherence to antiretroviral therapies (Corless et al 2013). In addition, mental health issues, such as depression, remain prevalent among people with HIV, and guidelines have been developed for the psychological support of adults living with HIV (British Psychological Society et al 2011).

Many patients with HIV experience additional psychological pressures caused by stigma and discrimination related to living with the condition, which prevent them from accessing healthcare services or communicating their concerns. The British Psychological Society et al (2011) guidelines recommend that patients with HIV should receive screening for their psychological well-being every 12 months, or at specific points that are known to trigger or exacerbate mental distress, such as starting treatment, disease progression, bereavement and relationship issues. The quality of life of patients with HIV may be divided into physical, psychological, social, and environmental concerns (Table 1) (Basavaraj et al 2010, Tran et al 2012). Care for patients with HIV should encompass all of these concerns to improve patient outcomes.
Effective communication between patients with HIV and healthcare professionals is essential, because it can affect patient satisfaction, adherence to treatment, and health outcomes (Laws et al 2012). The effectiveness of the relationship between patients and healthcare professionals depends on factors such as participatory or collaborative decision-making, general communication, and trust (Schneider et al 2004).

In many cases, individuals with HIV do not actively engage with their healthcare teams to discuss their wellbeing. This may arise from a sense of deference to healthcare professionals, embarrassment, misplaced stoicism, or an assumption that the healthcare professional will ask the patient directly about their well-being (Mimiaga et al 2007). Healthcare professionals might assume that patients will volunteer their concerns without prompting, or they might avoid discussing some subjects to avoid embarrassing the patient (Verhoeven et al 2003). Another barrier to effective communication between patients and healthcare professionals may be that increased pressure on resources has reduced the length of consultation times (Ogden et al 2004).

The British HIV Association (2013) standards of care 6 and 10 state that patients with HIV should be engaged with self-management programmes and

TABLE I. Potential quality of life concerns for patients with human

immunodeficiency virus and acquired immune deficiency syndrome

\begin{tabular}{|c|c|c|c|}
\hline Physical & Psychological & Social & Environmental \\
\hline $\begin{array}{l}\text { » Activities of daily living } \\
\text { » } \text { Dependence on } \\
\text { prescribed medicines } \\
\text { or illicit substances } \\
\text { » Energy levels } \\
\text { » Fatigue } \\
\text { » Mobility } \\
\text { » Pain and discomfort } \\
\text { » Perceived capacity } \\
\text { to work } \\
\text { » Sleep behaviour }\end{array}$ & $\begin{array}{l}\text { " Anxiety } \\
\text { " Body image } \\
\text { " Depression } \\
\text { " Higher cognitive } \\
\\
\text { functions } \\
\text { " Negative and positive } \\
\text { thoughts and feelings } \\
\text { " Self-esteem } \\
\text { " Spirituality }\end{array}$ & $\begin{array}{ll}\text { » } & \text { Ability to maintain } \\
\text { social contacts } \\
\text { " Effects on personal } \\
\text { relationships } \\
\text { » } \text { Sexual activity } \\
\text { » } \text { Social support }\end{array}$ & $\begin{array}{l}\text { " Ability to engage in } \\
\text { hobbies and activities } \\
\text { \# Freedom } \\
\text { " Financial status } \\
\text { Physical safety and } \\
\text { security } \\
\text { Quality of home } \\
\text { environment }\end{array}$ \\
\hline
\end{tabular}




\section{KEY POINT}

It is important that patients with HIV understand their condition and treatment.

Failure to engage effectively with patients can undermine their confidence and be a barrier to treatment. Strategies are required in clinical practice to encourage and support effective communication between patients and healthcare professionals actively involved in treatment decisions; these are the cornerstones of managing patients with HIV, as with any care delivered by the NHS (Department of Health 2012). These standards emphasise that low health literacy contributes to suboptimal care and worse health status for patients (British HIV Association 2013). Therefore, it is important that patients with HIV understand their condition and treatment. Failure to engage effectively with patients can undermine their confidence and be a barrier to treatment. Strategies are required in clinical practice to encourage and support effective communication between patients and healthcare professionals.

\section{Development of the wellness thermometer}

To overcome some of the communication challenges experienced by healthcare professionals and patients, a holistic assessment tool could be used that considers the psychological, spiritual, financial and social issues that patients with HIV might encounter. Such a tool should be easy to use to appeal to patients and to take into account the potential variation in their literacy levels. There is a precedent for such an approach, because several tools are available to support communication between patients and healthcare professionals. For example, the distress thermometer was developed specifically for use in oncology (Vitek et al 2007). This has been reported to be an economical and useful screening tool in cancer care, and it enables the identification of patients' practical, family, emotional, spiritual and physical issues (Vitek et al 2007, Iskandarsyah et al 2013, Loquai et al 2013).

To develop a similar screening tool for use in HIV care, the distress thermometer was adapted by a national multidisciplinary working group, and renamed the wellness thermometer (Figure 1).

The aim was to develop a tool to assist in the monitoring of the biological, psychological, social and spiritual well-being of patients with HIV. The term 'wellness' was used to promote the concept of living well with HIV and to move beyond a disease-focus in healthcare.

The national multidisciplinary working group comprised experts in the field of HIV, including a psychologist, consultant physicians and specialist nurses, as well as patient experts to capture the patient's perspective of living with HIV. The working group explored optimal ways to capture patients' concerns and to encourage patients with HIV to engage in conversations with healthcare professionals about their treatment. After consultation with the working group, it was agreed that the tool should be:

»Easy for patients to use.

"Convenient for use in clinical practice, with the aim of making consultations shorter and easier.

» Easy to interpret and identify any potential concerns in relation to patients' treatment that might require increased monitoring or intervention.

The distress thermometer was adapted to change the focus from the acute setting to the chronic setting. The multidisciplinary working group developed the wellness thermometer through multiple rounds of discussion, review, and consensus, using an adapted Delphi technique.

The multidisciplinary working group identified common side effects associated with HIV and treatment, including the emotional and psychological issues commonly experienced by patients with HIV, such as depression, feelings of embarrassment and challenges associated with living with HIV, and adapted the wellness thermometer accordingly. The language used in the wellness thermometer was carefully chosen to be accessible to the general public and patients with low-level literacy skills, to encourage patients to disclose any concerns they had. The score from 1 to 10 on the wellness thermometer is intended to encourage discussion about why the patient has given a particular score, and what would have to change to improve the score.

The patient completes the wellness thermometer before the consultation. 
However, the healthcare professional should check the patient's literacy level in the first instance, and provide assistance if required.

The wellness thermometer was developed to be user-friendly for healthcare professionals. The tool is self-explanatory and its results are easy to interpret. Some of the items on the wellness thermometer may indicate the patient is experiencing psychosocial issues that may be beyond the capacity or expertise of some healthcare professionals. Such issues should be managed by referring patients to the appropriate specialist resources and services, where

Figure I. Wellness thermometer

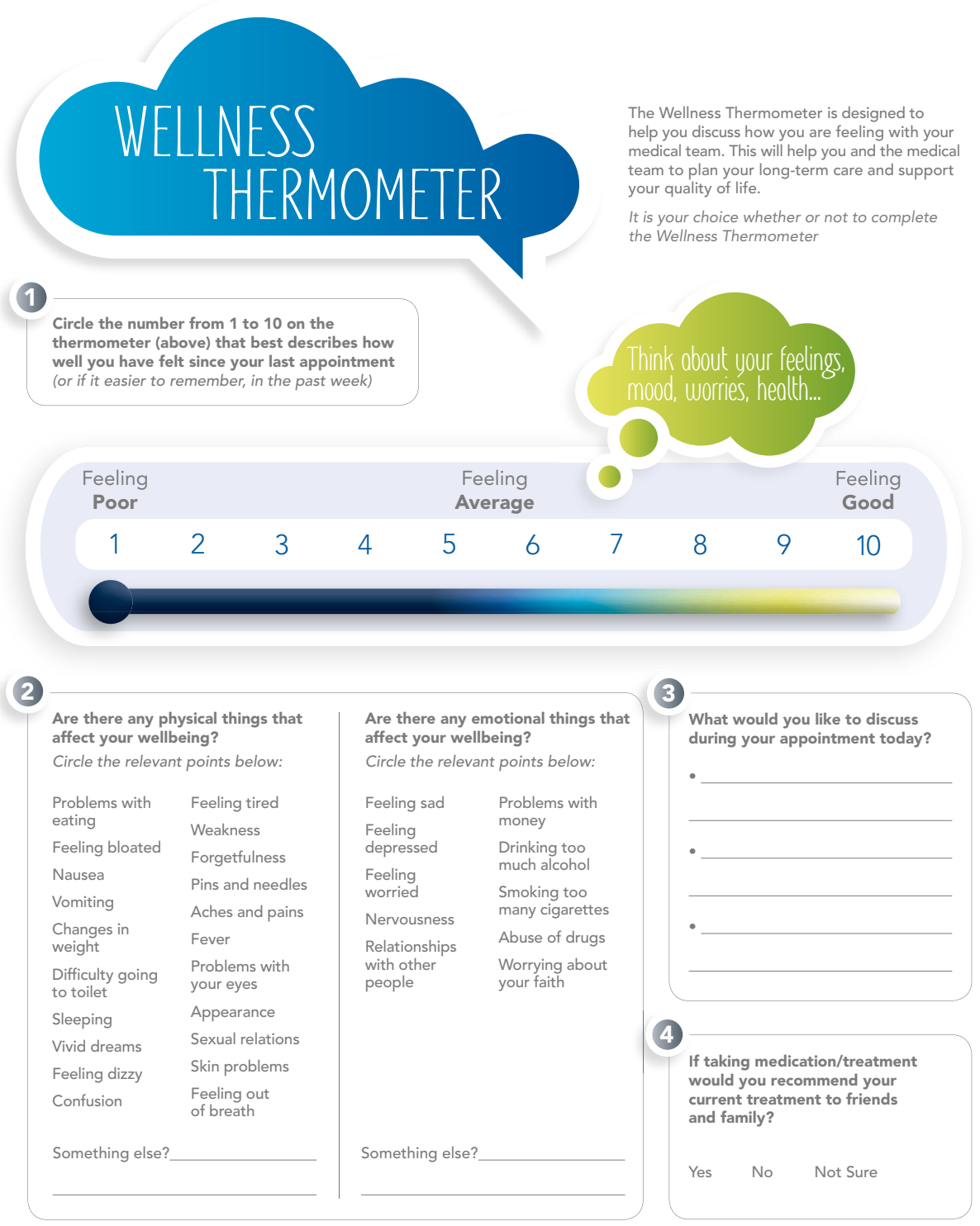


possible. The wellness thermometer supports healthcare professionals in listening to the patient's concerns and referring them to other services, where possible and appropriate.

Once the wellness thermometer had been developed, the multidisciplinary working group wanted to establish whether it improved healthcare consultations. A service evaluation was undertaken to establish the benefits of using the wellness thermometer in clinical practice.

\section{Aim \\ To evaluate the effectiveness of using the wellness thermometer in healthcare consultations with patients with HIV.}

\section{Method}

The wellness thermometer was offered to all patients who attended three UK HIV clinics over an eight-week period, from March to April 2014. Clinics in large teaching hospitals and smaller district hospitals were selected to ensure that the tool was suitable for various settings.
Patients were given the wellness thermometer to complete before their consultation at the HIV clinic. After their consultation, patients were given a short anonymous survey to evaluate their views of using the tool. Patients were asked to give a rating that ranged from 'strongly agree' to 'strongly disagree' in response to a set of statements about the wellness thermometer.

Patients were asked to rate the usefulness of being able to record their overall wellbeing, specific issues in relation to their well-being and to write down what they wanted to discuss in the consultation. Participating healthcare professionals were invited to complete a short anonymous survey to provide their opinions and experiences of using the wellness thermometer. Healthcare professionals were asked to give a rating that ranged from 'strongly agree' to 'strongly disagree' in response to a set of statements about the wellness thermometer. Verbal feedback was also encouraged to gain an understanding of healthcare professionals' experiences and the acceptability of using the tool in consultations.

TABLE 2. Patients' responses to statements about the use of the wellness thermometer ( $n=231)$

\begin{tabular}{|c|c|c|c|c|c|c|}
\hline & $\begin{array}{l}\text { Strongly agree } \\
\quad \%\left(\mathrm{No}_{0}\right)\end{array}$ & Agree \% (No.) & $\begin{array}{l}\text { Neither agree } \\
\text { or disagree \% } \\
\text { (No.) }\end{array}$ & $\begin{array}{l}\text { Disagree \% } \\
\quad \text { (No.) }\end{array}$ & $\begin{array}{l}\text { Strongly } \\
\text { disagree \% } \\
\text { (No.) }\end{array}$ & $\begin{array}{l}\text { Not completed } \\
\%(\mathrm{No} .)\end{array}$ \\
\hline $\begin{array}{l}\text { The wellness thermometer helped to } \\
\text { identify my concerns }\end{array}$ & $29(68)$ & $51(117)$ & $16(36)$ & $1(3)$ & $3(7)$ & $0(0)$ \\
\hline $\begin{array}{l}\text { The wellness thermometer improved my } \\
\text { conversation with my doctor/nurse }\end{array}$ & $29(66)$ & 50 (116) & 15 (34) & $3(7)$ & $3(8)$ & $0(0)$ \\
\hline $\begin{array}{l}\text { The wellness thermometer helped me to } \\
\text { bring up my concerns with my doctor/ } \\
\text { nurse }\end{array}$ & $35(81)$ & 46 (107) & $12(28)$ & $3(6)$ & $3(8)$ & 0 (1) \\
\hline $\begin{array}{l}\text { The wellness thermometer will help } \\
\text { me record my concerns between } \\
\text { appointments }\end{array}$ & $30(70)$ & $46(106)$ & $17(40)$ & 2 (5) & $3(7)$ & $1(3)$ \\
\hline $\begin{array}{l}\text { I would recommend the wellness } \\
\text { thermometer to a friend or family member } \\
\text { with a health problem }\end{array}$ & $35(81)$ & $45(105)$ & $13(30)$ & $3(6)$ & $3(8)$ & $0(1)$ \\
\hline $\begin{array}{l}\text { I would recommend the wellness } \\
\text { thermometer to other people with my } \\
\text { condition }\end{array}$ & 36 (83) & 47 (109) & $10(24)$ & $3(6)$ & $3(8)$ & 0 (1) \\
\hline
\end{tabular}




\section{Ethical issues}

In line with clinical governance, the project was registered with North Manchester General Hospital's research and development department. Using the NHS Health Research Authority decision tool (www.hra-decisiontools.org.uk/ research), this project was not designated as clinical research. The members of the multidisciplinary working group gave informed verbal consent to participate in the development of the wellness thermometer.

Participants were informed they were free to refuse to participate or to withdraw from the project at any time. The evaluation of the tool's effectiveness in clinical practice was viewed as a service evaluation, and therefore did not require ethical approval.

\section{Results}

\section{Patients' experience of using the} wellness thermometer

A total of 231 patients completed the survey. Patients were asked to rate a set of statements about the use of the wellness thermometer on a Likert scale, which ranged from 'strongly agree' to 'strongly disagree'. The majority of responses were 'strongly agree' or 'agree' (Table 2).

Most patients reported positive experience of using the wellness thermometer. The results suggest that the wellness thermometer was well-received by patients with HIV and that it enhanced their ability to communicate their concerns to healthcare professionals. The data demonstrated that use of the wellness thermometer could be valuable for patients in terms of enhancing their relationships with their healthcare teams and enabling them to communicate any concerns they have in relation to their treatment or quality of life.

\section{Healthcare professionals' experience of using the wellness thermometer}

The 12 healthcare professionals who participated in the service evaluation reported that they felt the wellness thermometer helped patients to identify their concerns $(n=10)$ and most felt the wellness thermometer was easy to use $(n=11)$. There were mixed responses about whether the wellness thermometer improved consultations; seven healthcare professionals felt that it did, while five healthcare professionals felt it did not (Table 3).

Informal feedback from the healthcare professionals in the service evaluation, revealed that they felt the wellness thermometer gave structure to the consultation, which enabled them to address the patient's concerns in the first instance. This made addressing the routine

TABLE 3. Healthcare professionals' responses to statements about the use of the wellness thermometer $(n=12)$

\begin{tabular}{c|c|c|c} 
Strongly agree & Agree (No.) & Neither agree or & Disagree (No.)
\end{tabular}

3

The wellness thermometer helped my patients identify their concerns

The wellness thermometer improved consultations

The wellness thermometer is easy to understand

The wellness thermometer resulted in longer consultations

I think the wellness thermometer is a useful tool

I would like to use the wellness thermometer in all my patients 


KEY POINT
Effective communication
between patients with
HIV and healthcare
professionals is essential.
Patients should feel
empowered to inform
their healthcare team of
concerns about all aspects
of living with HIV, including
those related to their
treatment and quality of life

aspects of care, for example discussing

blood test results, less complex.

When implementing the wellness thermometer, some healthcare professionals raised the issue of the time pressure of consultations, with some expressing concerns that using the wellness thermometer would result in longer consultations. However, feedback from healthcare professionals who used the wellness thermometer in the service evaluation, suggested that its use did not significantly add to the length of consultations.

All participating healthcare professionals reported positive experience of using the wellness thermometer, and stated they would use the tool beyond the service evaluation to enhance healthcare consultations.

\section{Discussion}

Patients with HIV experience a range of challenges associated with living with a long-term condition and its treatment, and therefore it is necessary for healthcare professionals to engage with these patients holistically. Long-term monitoring of patients with HIV should capture qualitative and quantitative information about patients' well-being. Monitoring patients' holistic well-being is also important because improved wellbeing can lead to improved adherence to treatment, which ultimately results in improved morbidity and mortality. The authors believe routine and recordable monitoring of well-being should become an essential aspect of each healthcare consultation for patients with HIV, and the wellness thermometer could be used to achieve this.

Effective communication between patients with HIV and healthcare professionals is essential. Patients should feel empowered to inform their healthcare team of concerns about all aspects of living with HIV, including those related to their treatment and quality of life. Healthcare professionals should have a means to talk to patients and encourage them to discuss any concerns they may have about their quality of life, since these may be indications of potential issues with the treatment regimen, challenges adjusting to living with HIV, social factors such as stigma or financial issues, and other co-morbid health issues that require effective communication with other healthcare services.

The wellness thermometer could be used as part of routine HIV care to enable patients to be increasingly involved in their care and to ensure routine, time-limited consultations remain patient-centred.

\section{Limitations}

This was a UK-based evaluation of the effectiveness of the wellness thermometer in identifying the concerns of patients with HIV. The study did not take into consideration the global burden of HIV or how transferable this tool would be in other countries, to assist healthcare professionals in identifying patients' concerns. The study was also limited to patients with HIV; however, the principles of the wellness thermometer could be adapted for use with patients who have other conditions. Therefore, further research is required to establish if the wellness thermometer could be used in various countries and for other conditions.

\section{Conclusion}

The authors hope the wellness thermometer will support patients with HIV to identify and discuss their concerns, in relation to their treatment and quality of life, and improve communication between patients and healthcare professionals. The authors hope that the wellness thermometer will be used as part of routine HIV care to enable patients to be increasingly involved in their care and to ensure healthcare consultations to remain patient-centred.

Most patients who participated in the evaluation reported positive experiences of using the wellness thermometer. Most patients felt that the tool helped to identify their concerns, improved their conversation with the healthcare professional and helped them raise their 
concerns in healthcare consultations. Most healthcare professionals agreed that the wellness thermometer is a useful tool and felt it helped patients with HIV to identify their concerns. The authors believe the wellness thermometer enables routine and recordable monitoring of patients' well-being. It is envisaged that the wellness thermometer could become a useful tool for improving communication between patients with HIV and healthcare professionals.

\section{IMPLICATIONS FOR PRACTICE}

"The wellness thermometer is an easy to use, holistic assessment tool that enables patients to identify their concerns before their healthcare consultations.

» The wellness thermometer supports patientcentred consultations, and could be used by healthcare professionals to identify the concerns patients with HIV may have about their treatment or quality of life.

"Nurses should consider that patients value being assessed holistically and being involved in their care.

\section{References}

Antiretroviral Therapy Cohort Collaboration (2008) Life expectancy of individuals on combination antiretroviral therapy in highincome countries: a collaborative analysis of 14 cohort studies. The Lancet. 372, 9635, 293-299.

Basavaraj KH, Navya MA, Rashmi R (2010) Quality of life in HIV/AIDS. Indian Journal of Sexually Transmitted Diseases and AIDS. 31, 2,75-80.

British HIV Association (2013) British HIV Association Standards of Care for People Living with HIV 2013. Mediscript, London.

British Psychological Society, British HIV Association, Medical Foundation for Aids and Sexual Health (2011) Standards for Psychological Support for Adults Living with HIV. MedFASH, London.

Corless IB, Voss J, Guarino AJ et al (2013) The impact of stressful life events, symptom status, and adherence concerns on quality of life in people living with HIV. Journal of the Association of Nurses in AIDS Care. 24, 6, 478-490.

Degroote S, Vogelaers DP, Vermeir P et al (2013) Socio-economic, behavioural, (neuro) psychological and clinical determinants of HRQoL in people living with HIV in Belgium: a pilot study. Journal of the International AIDS Society. 16, 1, 18643.

Department of Health (2012) Liberating the NHS: No Decision About Me, Without Me: Further Consultation on Proposals to Secure Shared Decision-Making. The Stationery Office, London.

Iskandarsyah A, de Klerk C, Suardi DR et al (2013) The Distress Thermometer and its validity: a first psychometric study in Indonesian women with breast cancer. PloS One. 8, 2, e56353.

Laws MB, Rose GS, Bezreh T et al (2012) Treatment acceptance and adherence in HIV disease: patient identity and the perceived impact of physician-patient communication
Patient Preference and Adherence. 6, 893-903.

Loquai C, Scheurich V, Syring N et al (2013) Screening for distress in routine oncological care: a survey in 520 melanoma patients. PLOS One. 8, 7, e66800.

Mimiaga MJ, Goldhammer H, Belanoff C et al (2007) Men who have sex with men: perceptions about sexual risk, HIV and sexually transmitted disease testing, and provider communication. Sexually Transmitted Diseases. $34,2,113-119$.

Ogden J, Bavalia K, Bull M et al (2004) 'I want more time with my doctor': a quantitative study of time and the consultation. Family Practice. $21,5,479-483$.

Samji H, Cescon A, Hogg RS et al (2013) Closing the gap: increases in life expectancy among treated HIV-positive individuals in the United States and Canada. PLOS One. 8, 12, e81355.

Schneider J, Kaplan SH, Greenfield S et al (2004) Better physician-patient relationships are associated with higher reported adherence to antiretroviral therapy in patients with HIV infection. Journal of General Internal Medicine. $19,11,1096-1103$.

Thompson MA, Aberg JA, Hoy JF et al (2012) Antiretroviral treatment of adult HIV infection: 2012 recommendations of the International Antiviral Society-USA panel. JAMA. 308, 4, 387-402.

Tran BX, Ohinmaa A, Nguyen LT (2012) Quality of life profile and psychometric properties of the EQ-5D-5L in HIV/AIDS patients. Health and Quality of Life Outcomes. 10, 132. doi: 10.1186/1477-7525-10-132.

Verhoeven V, Bovijn K, Helder A et al (2003) Discussing STIs: doctors are from Mars, patients from Venus. Family Practice. 20, 1, 11-15.

Vitek L, Rosenzweig MQ, Stollings S (2007) Distress in patients with cancer: definition, assessment, and suggested interventions. Clinical Journal of Oncology Nursing. 11, 3, 413-41. 